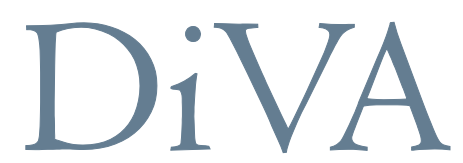

http://uu.diva-portal.org

This is an author produced version of a paper published in Evolutionary Ecology. This paper has been peer-reviewed but does not include the final publisher proof-corrections or journal pagination.

Citation for the published paper:

Abbott, Jessica K.; Svensson, Erik I.

"Ontogeny of sexual dimorphism and phenotypic integration in heritable morphs"

Evolutionary Ecology, 2008, Vol. 22, Issue 1, pp. 103-121

http://dx.doi.org/10.1007/s10682-007-9161-0

The original publication is available at springerlink.com. Access to the original publication may require subscription. 


\section{Ontogeny of sexual dimorphism and phenotypic integration in}

\section{heritable morphs}

J. K. Abbott ${ }^{1 *}$ and E. I. Svensson ${ }^{1}$

1. Section for Animal Ecology, Ecology Building, Lund University SE-223 63 Lund, SWEDEN. Phone: +46 46222 3701, Fax: +4646 2224716

*Author for correspondence: Jessica.Abbott@zooekol.lu.se

Running title: Sexual dimorphism and phenotypic integration in heritable morphs

Keywords: alternative phenotypes, antagonistic selection, complex life-cycle, correlational selection, mimicry, sexual conflict 


\section{Abstract}

3 In this study we investigated the developmental basis of adult phenotypes in a non-model

4 organism, a polymorphic damselfly (Ischnura elegans) with three female colour morphs. This

5 polymorphic species presents an ideal opportunity to study intraspecific variation in growth

6 trajectories, morphological variation in size and shape during the course of ontogeny, and to

7 relate these juvenile differences to the phenotypic differences of the discrete adult phenotypes;

8 the two sexes and the three female morphs. We raised larvae of different families in

9 individual enclosures in the laboratory, and traced morphological changes during the course

10 of ontogeny. We used principal components analysis to examine the effects of Sex, Maternal

11 morph, and Own morph on body size and body shape. We also investigated the larval fitness

12 consequences of variation in size and shape by relating these factors to emergence success.

13 Females grew faster than males and were larger as adults, and there was sexual dimorphism in

14 body shape in both larval and adult stages. There were also significant effects of both

15 maternal morph and own morph on growth rate and body shape in the larval stage. There were

16 significant differences in body shape, but not body size, between the adult female morphs,

17 indicating phenotypic integration between colour, melanin patterning, and body shape.

18 Individuals that emerged successfully grew faster and had different body shape in the larval

19 stage, indicating internal (non-ecological) selection on larval morphology. Overall,

20 morphological differences between individuals at the larval stage carried over to the adult

21 stage. Thus, selection in the larval stage can potentially result in correlated responses in adult

22 phenotypes and vice versa. 
24 Recent years have witnessed an increased interest in the relationship between development

25 and phenotype, and the problem of how integrated phenotypes evolve (West-Eberhard, 2003;

26 Pigliucci \& Preston, 2004). This problem is particularly interesting in the context of heritable

27 phenotypic polymorphisms, in which distinct alternative phenotypes maintain their integrity

28 and multitrait differences, despite being controlled by, in many cases, only one or a few

29 genetic loci (Sinervo \& Lively, 1996; Shuster \& Sassaman, 1997; Sinervo et al., 2000;

30 Svensson et al., 2001; Svensson et al., 2005; Leimar, 2005). There are many conceptual

31 similarities between the persistence of such multiple alternative phenotypes, or morphs, and

32 the evolution of gender differences and sexual dimorphism. Research on sexual size

33 dimorphism has recently focused on its developmental origins. Investigation of how the sexes

34 differ in growth rates and development time has shown that these factors can result in either

35 the enhancement or suppression of adult dimorphism (Badyaev et al., 2001b; Badyaev, 2002).

37 In addition, recent theoretical work has suggested that the evolution of sexual dimorphism or

38 heritable polymorphism may be as likely an outcome of disruptive selection as the splitting

39 and evolutionary branching of a population into different species (Bolnick \& Doebeli, 2003).

40 In both cases, intraspecific divergence between phenotypes is constrained by the process of

41 genetic recombination and genetic correlations between sexes or morphs (Rice \&

42 Chippindale, 2001; Sinervo \& Svensson, 2002).

44 Although evolutionary developmental biology ("evo-devo") is a rapidly growing discipline, 45 most research in this area is still focused on classical model organisms such Drosophila and 46 Danio (Arthur, 2002). Relatively little work has been performed using non-model organisms

47 in ecologically relevant contexts, which has consequently stimulated a recent interest in

48 "ecological and evolutionary developmental biology", or "eco-evo-devo" (Gilbert, 2001). 
49 Here we present the results from a study on the links between larval development and adult

50 phenotype in a non-model organism, a polymorphic damselfly. Genetic colour polymorphism

51 is very common in damselflies but is also present in many other taxa, so our study should

52 have implications beyond our particular study species.

54 Our study species, Ischnura elegans, has three female colour morphs. Previous work revealed

55 differences between the adult female morphs in fecundity (Svensson et al., 2005; Svensson \&

56 Abbott, 2005) and emergence time (Abbott \& Svensson, 2005). The female morphs in $I$.

57 elegans are maintained by frequency-dependent male-female mating interactions, in which a

58 morph's fecundity decreases as it becomes more common in the population (Svensson \&

59 Abbott, 2005). This effect arises because males are thought to form a search image towards

60 common female morphs, which leads to a form of apostatic selection in which common

61 morphs suffer disproportionately from excessive male mating harassment (Fincke, 2004;

62 Svensson et al., 2005). Although researchers have suggested that there may also be

63 differences between the morphs in the larval stage (Cordero, 1992a; Cordero et al., 1998), we

64 are not aware of any studies by other researchers that have investigated this possibility.

65 Differences in emergence and development time between the morphs (Abbott \& Svensson,

66 2005) imply that there should be morph-related differences expressed in the larval stage. This

67 motivated us to investigate the differences in larval growth rate and body shape and their links

68 to phenotypic differences in the adult stage, and hence evidence for phenotypic integration

69 between growth rate, shape and color of the morphs (phenotypic integration, as defined by

70 Pigliucci (2003), is "the pattern of functional, developmental and/or genetic correlation

71 (however measured) among different traits in a given organism"). We also present data on the

72 ontogeny of sexual dimorphism in this species. One of our goals with this study is to integrate

73 the study of sexual dimorphism with the study of the developmental origins of heritable 
74 morphs, a synthesis that is clearly needed and in which only the first steps have recently been

75 taken (Badyaev, 2002; West-Eberhard, 2003; Sinervo and Svensson, 2004).

\section{Materials and methods}

79 Study species

81 Ischnura elegans is a small species of annual damselfly that can be found in ponds set in open

82 landscapes across Europe from southern Sweden to northern Spain (Askew, 1988). Adult

83 females lay eggs in the summer which hatch after several weeks and overwinter as larvae,

84 emerging as adults the following summer. Although males are monomorphic, adult female $I$.

85 elegans are trimorphic. One of the morphs, the Androchrome (A), is blue and black like a

86 male, with male-like black patterning on the thorax, and is considered to be a male mimic

87 (Cordero et al., 1998). The other two morphs, Infuscans (I) and Infuscans-obsoleta (IO), are

88 more cryptic and are green/brown and black (Askew, 1988). Of these two, Infuscans females

89 have black patterning on the thorax similar to males and Androchrome females, while

90 Infuscans-obsoleta females have a unique and less extensive black patterning on the thorax.

92 The development of the female morphs of I. elegans is controlled by a single locus with three

93 alleles, similar to the closely related species, I. graellsii (Cordero, 1990; Sánchez-Guillén et

$94 a l ., 2005)$. The three alleles form a dominance hierarchy, with the A-allele being dominant to

95 the I- and IO-alleles, the I-allele recessive to the A-allele but dominant to the IO-allele, and

96 the IO-allele recessive to both the other alleles (A>I>IO, Sánchez-Guillén et al., 2005).

97 Although larvae of both sexes and adult males all carry the morph alleles, the colour morphs

98 are only expressed in adult females, hence this is both a stage- and sex-limited polymorphism. 
100 Morphological measurements

102 We collected eggs from damselflies from a natural population, Vombs Vattenverk, outside

103 Lund, in southern Sweden in the summer of 2002. We intended to collect eggs from this

104 population only, but it proved impossible to obtain a balanced data set in this way, due to

105 insufficient numbers of the rarest morph (Infuscans-obsoleta). Because of this, some clutches

106 of eggs (14 out of a total of 81 clutches) came from females captured at some of the other 13

107 populations we have investigated (see Svensson et al., 2005; Lomma, Hofterupssjön, Höje å

108 6, Höje å 7, Höje å 14, Flyinge 30A3, and Genarp).

110 Mature females of all three morphs were brought back to the laboratory and placed in

111 ovipositoria, small containers with damp filter paper at the bottom. After 48 hours the

112 females were removed and the eggs stored in water until they hatched. After hatching, larvae

113 were transferred to large plastic containers and fed with brine shrimp (artemia) daily. We

114 transferred up to ten larvae from each family to individual enclosures within the plastic

115 containers approximately one month after hatching, in order to prevent cannibalism. If more

116 than 10 individuals from the same family were available, the extra individuals were kept but

117 are not included in the analysis of growth trajectories. The individual enclosures contained

118 wooden perches for damselflies to crawl up during emergence.

120 Larvae were kept under a constant temperature and light regime (temperature: $17^{\circ} \mathrm{C}$, light

121 regime: 12:12) and were maintained in the lab until emergence next spring (2003).

122 Individuals in the lab emerged several months earlier than individuals in the field (in January-

123 May of 2003, rather than May-August), which is probably an effect of temperature rather than 
124 photoperiod (de Block \& Stoks, 2003). Though temperature affects overall timing of

125 emergence, it does not appear to affect the relative emergence times of the morphs, the sexes,

126 or their final size and shape, since a repetition of the same experiment the following year

127 using two different temperature treatments $\left(12^{\circ} \mathrm{C}\right.$ and $\left.21^{\circ} \mathrm{C}\right)$ did not show any significant

128 effects of temperature on these measurements (Abbott, unpublished data). Once they had

129 been transferred to the individual containers, each larva was given a unique identification

130 number and measured under a light microscope once every 3-4 weeks until emergence. We

131 measured total length (excluding gills), abdomen length, thorax width, width of the $4^{\text {th }}$

132 segment of the abdomen (S4), and wing pad length (because damselflies are not

133 holometabolous wing development begins in the larval stage), and also determined the sex of

134 the larva by examination of the underside of the abdomen. Damselfly larvae go through

135 several instars before reaching maturity and therefore grow in stages. This means that some

136 individuals might not have reached the next instar between measurement times and should

137 therefore have remained the same size. In a few cases size measurements decreased slightly

138 between measurement times. We then assumed that this was due to measurement error, and

139 took the average of both these measurements.

141 Adults were measured and, in the case of females, marked for identification and placed in

$14250 * 50 * 50 \mathrm{~cm}$ insectaria containing water and Drosophila until their morph could be

143 determined (no more than 25 females were housed in an insectarium at a time). We measured

144 the same traits in adults as in larvae (total length, abdomen length, thorax width, S4 width, 145 and wing length).

147 Statistics 
149 Principal components analysis was performed on larval measurements, and the first two

150 components were found to be suitable for further analysis. After the larvae had been moved

151 into the individual enclosures we started recording individual mortality.

153 Ontogenetic changes in size and shape (PC1 and PC2) were investigated using repeated

154 measures (PROC MIXED, SAS, Littell et al., 1996). The correct covariance structure was

155 determined by comparing the Akaike Information Criterion (AIC). We investigated the 156 effects on PC1 and PC2 of the fixed factors Maternal morph and Sex in all individuals, and of

157 Own morph in females only. We also investigated whether there was any difference in 158 developmental trajectories between individuals that managed to emerge successfully and

159 those that did not. Family was included as a random factor in all analyses, except of the effect

160 of own morph on PC1, to control for non-independence of siblings (Fry, 1992). It was

161 impossible to include Family as random factor in the analysis of the effect of Own morph on

$162 \mathrm{PC} 1$, probably because this subset of the data was too unbalanced, so in this case, Family was

163 included as a fixed factor instead. Two-way interactions between all factors (except

164 Sex*Morph since males are monomorphic and Morph*Emergence since we could not

165 determine morph for females that died in the larval stage) were also tested but this did not

166 change the results, so for simplicity interaction effects will not be presented here. An analysis

167 of the effect of Maternal morph on PC2 for males only was also carried out, to see whether

168 differences between offspring of the morphs were due to biased sex ratios.

170 We also looked at the effects of Sex, Maternal morph, Own morph, and whether the

171 individual emerged successfully on morphology in the last instar using a mixed model with

172 Family as a random factor. 
174 We analysed the probability of emerging according to Sex and Maternal morph with Family

175 as a random factor using a generalized linear model (GLIMMIX macro in SAS, Littell et al., 176 1996) with binomial error and logit link function. This was done to investigate if differences

177 between individuals that emerged and those that did were possibly confounded by differences

178 in survival rates between the sexes, between offspring of the female morphs, or between

179 families,

181 A separate principal components analysis was performed on the lab-raised adults, and again,

182 the first two components were selected for further analysis. Mixed model analyses with

183 Family as a random factor nested within Maternal morph were performed in SAS (Littell et

184 al., 1996). Family was nested within Maternal morph because each Family can by definition

185 only have one value for Maternal morph, precluding any interaction between these two factors 186 (Abbott \& Svensson, 2005). We analysed the effects of Sex and Maternal morph on PC1 and 187 PC2 in all individuals, and the effects of Maternal morph and the individual's Own morph in 188 females only. All analyses included interactions between fixed factors. Post-hoc comparisons 189 of least square means were carried out for significant effects.

191 To investigate if any differences between groups were confounded by population effects, we 192 included Population as a random factor in all analyses, both of larval growth trajectories and 193 adult morphology. Population was never significant (all $P$-values $>0.10$ ) and did not affect 194 our results, so we only present models here that do not include Population as a factor.

196 Finally, we calculated phenotypic correlations between traits in the final larval instar and the 197 same trait in the adult stage, using STATISTICA (Statsoft 2004). 


\section{Results}

201 Mortality

203 Mortality was relatively modest; $28 \%$ of all individually tracked larvae died (227/806

204 individuals). By plotting a histogram of wing pad lengths we were able to identify when 205 individuals had reached the last instar (in this case, when wing pad length was greater than $2063.5 \mathrm{~mm}$ (Benke, 1970)). Most of these individuals $(174 / 806$, or $21 \%)$ died when in early

207 instars, not long after being moved into the individual enclosures, probably as a result of the 208 changed environmental conditions. These individuals were excluded from all further 209 analyses. The remainder (53/806, or 7\%) died in the last instar, close to or during emergence.

210 We believe that it is unlikely that individuals that had survived several months after being

211 moved into the individual enclosures suddenly died because of the conditions in the lab, and

212 so we assumed that this later mortality was related to problems during emergence. Probability

213 of emerging was not related to Maternal morph $\left(\mathrm{F}_{2,618}=0.12, P=0.8884\right)$, $\operatorname{Sex}\left(\mathrm{F}_{1,628}=0.68\right.$,

$214 P=0.4110)$, or Family $\left(\mathrm{F}_{78,628}<0.01, P>0.99\right)$ so differences between individuals that emerged

215 and those that did not are not a result of differential mortality between these groups.

217 Larval morphology

219 The principal components analysis of larval morphology indicated that PC1 was a measure of 220 overall size, which accounted for most of the variation in morphology (96\%). There was also 221 a minor component of the variation $(2.7 \%)$ which was related to variation in shape, such that 222 positive values of PC2 indicate a longer abdomen and shorter wings, while negative values 223 indicate a shorter abdomen and longer wings (Table 1). The last three PCs accounted for less 
224 than $1 \%$ of the variation each. Although PC2 accounted for a small part of the total variation, 225 this is probably due to the nature of the data set (a growth series). According to Jackson 226 (1991), in cases where the first principal component accounts for an overwhelming part of the

227 variation in the data it may still be appropriate to include other PCs in the analysis as long as

228 they are informative, i.e. the PC has an eigenvalue unequal to all subsequent PCs. Since the 229 difference in eigenvalue between PC2 and PC3 is almost three and a half times greater than 230 the difference in eigenvalue between PC3 and PC4 (0.093 versus 0.027$)$, we believe that PC2

231 is actually capturing an important and informative, if relatively small, part of the total

232 variation. In addition, $\mathrm{PC} 2$ in the larval and adult stages both indicate a negative relationship

233 between wing length and abdomen length, as does PC2 in an analysis of morphology of field-

234 caught adults (Abbott and Svensson, unpublished data), all of which suggests that the pattern 235 seen in PC2 in the larval stage is informative.

237 We found significant effects of all factors tested on body size (PC1) and body shape (PC2).

238 In these analyses, significant effects indicate differences between the equations of the best-fit

239 lines which describe the data. Main effects correspond to differences in intercept, the

240 factor*time interactions to differences in slope, and the factor*time ${ }^{2}$ interactions to differences 241 in curvature (Littell et al., 1996). For body size, we found that females had a higher growth 242 rate than males, that offspring of Infuscans-obsoleta females had a higher growth rate than the 243 offspring of the other two morphs, and that Androchrome females had a slightly higher 244 growth rate than females of the other two morphs (Table 2, Figure 1A-C). Individuals that 245 managed to emerge had a higher growth rate than individuals that did not emerge (Table 2, 246 Figure 1D). Females in the last instar were significantly larger than males in the last instar $247 \quad\left(\mathrm{~F}_{1,632}=141.70, P<0.0001\right)$, Androchrome females were significantly larger than Infuscans 248 females in the last instar $\left(\mathrm{F}_{2,229}=5.91, P=0.0032\right)$, and individuals that emerged successfully 
249 were larger in the last instar than individuals that did not emerge $\left(\mathrm{F}_{1,628}=13.11, \mathrm{P}=0.0003\right.$;

250 Table 4).

252 For body shape, we found that males start off with shorter abdomens and longer wing pads

253 than females, but that they end up with longer abdomens and shorter wing pads (Table 3,

254 Figure 2A). We also found that offspring of Infuscans-obsoleta females have longer

255 abdomens and shorter wing pads than the offspring of the other two morphs (Figure 2B). This

256 pattern held even when only males were included in the analysis (quadratic time effect of

257 Maternal morph: $\mathrm{F}_{2,258}=318.27, P<0.0001$; pattern is the same as in Figure 2B), so this reflects

258 a real effect of Maternal morph on offspring morphology which cannot simply be a result of

259 biased sex or morph ratios in offspring. Individuals that managed to emerge initially had

260 shorter abdomens and longer wing pads (lower values of PC2) than individuals that did not,

261 with the reverse pattern later in development (Figure 2D). This was also evident in the last

262 instar, where individuals that emerged successfully had longer abdomens and shorter wing

263 pads than individuals that did not emerge $\left(\mathrm{F}_{1,628}=19.43, P<0.0001\right.$; Table 4$)$. This suggests the

264 existence of internal selection on body shape. There was also an effect of Own morph on body

265 shape, with rank order of the different morphs changing several times over development

266 (Figure 2C). The difference between the morphs in the final instar approached significance,

267 with Androchrome females having a more male-like morphology (higher value of PC2) than

268 the other two morphs $\left(\mathrm{F}_{2,229}=2.92, P=0.0560\right.$; Table 4$)$.

270 Laboratory-raised adults

272 Similar to the analysis of larval morphology, PCA on adult morphology resulted in PC1 as a

273 measure of overall size which accounted for $60.1 \%$ of the variation. PC2 was found to be a 
274 measure of shape which accounted for $26.5 \%$ of the variation, where positive values indicate

275 relatively longer abdomens, but shorter wings and narrower S4, and negative values indicate

276 relatively shorter abdomens, with longer wings and wider S4 (Table 5). All other PCs

277 accounted for a relatively small part of the variation (data not shown).

279 Males and females differed in both body size (females were larger, Table 6 and Figure 3) and 280 body shape (males have relatively longer abdomens, shorter wings, and narrower S4, Table 7

281 and Figure 4A). There were no differences in body size between the different morphs or

282 between the offspring of the different morphs. Females of different morphs did, however,

283 differ in body shape. Infuscans-obsoleta females had shorter abdomens, longer wings and

284 wider S4 (Figure 4B). There was no difference between the offspring of the three morphs in 285 body shape.

287 All phenotypic correlations between size measurements in larval and adult stages were highly 288 significant (Table 8), indicating that morphological differences carry over between the stages. 289 In addition, in 8 cases out of 10, the factor loading for a trait in the larval stage and in the 290 adult stage is the same (Tables 1 and 5), suggesting that the pattern of variation in size and 291 shape is similar in both stages.

\section{Discussion}

295 Sexual dimorphism and heritable polymorphism in I. elegans are characterized by phenotypic 296 integration of colour and morphology (this study), and differences in development time 297 between different phenotypes (Abbott \& Svensson, 2005). In addition, development rate 298 interacts with development time to influence size. In the sexes, size differences are enhanced 
299 by this interaction, while in the morphs, size differences are instead suppressed by the same

300 type of interaction.

Size differences

304 Sexual size dimorphism in vertebrates can result from differences in development time,

305 development rate or both these factors acting jointly (Badyaev, 2002). Here we have shown 306 that females have a higher larval growth rate than males (Figure 1A), and were larger in the

307 final instar (Table 4) and as adults (Figure 3). In a previous analysis of data from the same 308 laboratory-raised population (Abbott \& Svensson, 2005), we have shown that males emerged 309 earlier than females (protandry). Thus, sexual differences in development time and

310 development rate are acting jointly, and in the same direction, to promote sexual size 311 dimorphism in I. elegans.

313 In contrast, for the offspring of the different morphs, development time and development rate

314 cancel each other out with respect to size. Offspring of Infuscans-obsoleta females were found

315 to emerge earlier than the offspring of the other morphs (Abbott \& Svensson, 2005), but

316 despite this they do not differ in size as adults (Table 6). Instead, they grow faster in the larval

317 stage (Figure 1B), making them able to attain the same size in a shorter time. Androchrome

318 females had a slightly higher growth rate than the other two morphs were larger in the final

319 instar (Table 4), although the difference did not carry over to the adult stage. Since there was

320 no competition in our experimental design, this difference could be due to differences in

321 efficiency in obtaining and assimilating food. Adult Androchrome females have been found

322 to be larger than the other morphs in some populations (Cordero, 1992a), which was

323 suggested to be a result of competitive differences between morphs at the larval stage. Our 
324 results indicate that pleiotropic, physiological effects of the morph locus may also be

325 involved.

327 Shape differences

329 Shape differences between the sexes and the morphs were generally consistent between the

330 different life stages. In the adult stage, males have relatively longer abdomens, shorter wings,

331 and narrower S4 (Figure 4A) than females. This is consistent with their shape in the final

332 instar, where males have longer abdomens and relatively shorter wing pads than females

333 (Table 4). Similarly, the Infuscans-obsoleta morph was the most divergent morph in both

334 stages, although in the adult stage this was evident as an effect of the female's Own morph

335 (Figure 4B), while in the larval stage it was due to the effect of Maternal morph (Figure 2B,

336 comparing parental and offspring traits is a standard quantitative-genetic approach; see Abbott

$337 \&$ Svensson, 2005 for details).

339 Both size and shape differences seem to have additive genetic components, as indicated by the

340 significant effects of the factor Family on both PC1 (Tables 2 and 6) and PC2 (Tables 3 and

341 7). Body length has previously been demonstrated to be heritable in a related species

342 (Cordero, 1992b). Our findings that most of this genetic variation is aligned along the size

343 axis with less variation in shape is consistent with many other quantitative-genetic studies on

344 other organisms (Schluter, 1996). The phenotypic correlations found here also confirm that

345 larval and adult size and shape are related (Table 8), which has previously been shown for

346 size (Harvey \& Corbet, 1985; Banks \& Thompson, 1987; Cordero, 1992b). In the closely

347 related damselfly genus Enallagma, larval phenotypic traits influenced by selection imposed 
348 by different aquatic predators such as fish or dragonfly larvae may show a correlated response

349 to selection on reproductive traits in the adult stage (Stoks et al., 2003; Stoks et al., 2005).

351 Sexual dimorphism

353 Adult males of I. elegans are both smaller than females and different in shape, as well as

354 being monomorphic for colour (in contrast to the colour polymorphic females). The size 355 difference between the sexes is probably a result of selection for protandry (earlier emergence 356 of males), since males engage in scramble competition for females. Previous field studies

357 have shown that small males may have higher mating success in some populations (Cordero 358 et al., 1997; Carchini et al., 2000). For females, fecundity is likely to be more influenced by 359 body size than by timing of emergence (Cordero, 1991; Morbey \& Ydenberg, 2001). Thus, 360 sexual size dimorphism in this species may result from sexually antagonistic selection on 361 body size, with different size optima for males and females (Rice \& Chippindale, 2001). The 362 shape differences between the sexes should reflect adaptive differences arising from gender363 specific reproductive roles. Males must have relatively long abdomens for completion of the 364 wheel position during mating (Corbet, 1999) and females may have wider abdomens than 365 males in order to accommodate the ovaries. The presence of the ovaries implies that females 366 should be heavier than males of the same length, which may in turn select for longer wings.

368 We also note that the maternal morphs also influence the shape of their monomorphic sons 369 (Table 3 and Figure 2B). An analysis of the effect of Maternal morph on PC2 in only males 370 results in the same pattern as seen in Figure 2B, with male offspring of Infuscans-obsoleta 371 females having the most male-like shape in the larval stage. This may have some implications 372 for ontogenetic sexual conflict between loci affecting overall shape and the morph locus. We 
373 have previously argued in a similar vein that there is a conflict between loci for early

374 emergence favouring male protandry and the morph-locus which also influences development

375 time in both males and females (Abbott \& Svensson, 2005).

377 Phenotypic integration

379 The fact that the female morphs in I. elegans differ in colour (Askew 1988), shape and 380 development rate (this study), as well as development time (Abbott \& Svensson, 2005) and

381 fecundity (Svensson et al., 2005; Svensson \& Abbott, 2005), suggests that suites of 382 phenotypic traits are integrated in these morphs. This has some similarities to the adaptive 383 phenotypic integration documented for male secondary sexual characters in several avian 384 taxa, which are thought to be promoted by correlational selection for optimal character 385 combinations (Badyaev et al., 2001a; Badyaev, 2004a; Badyaev, 2004b; McGlothlin et al., 386 2005). Multi-trait differences between the morphs could have been caused by maternal 387 effects, pleiotropy, or linkage disequilibrium (Lynch \& Walsh, 1998) due to physical linkage 388 between loci for colour and morphology or which is built up in each generation by 389 correlational selection (Brodie, III, 1992). The data in this study do not allow us to 390 distinguish between these different explanations for the persistence of multi-trait differences 391 between these morphs.

393 The general pattern and direction of morph-specific differences in I. elegans are consistent 394 with the hypothesis that Androchrome females are male mimics, because they have both 395 male-like melanin patterning, male-like blue coloration, male-like behaviour (Van Gossum et 396 al., 2001) and they are also more male-like in shape (i. e. high value of PC2, cf. Figure 4). It 397 is possible that these striking and multiple phenotypic similarities between Androchromes and 
males are simply non-adaptive pleiotropic effects of the allele producing male-like coloration.

399 However, the observed pattern is certainly also consistent with selection to improve male

400 mimicry in Androchromes either through direct selection on shape, or indirectly via selection

401 for more male-like behaviour, such as flight or movement patterns, or as a response to

402 avoiding male mating harassment. For instance, morph-differences in relative wing to

403 abdomen length (i. e. PC2, see Fig. 4B) may affect flight speed or manoeuvrability, and

404 thereby success in escaping unwanted male mating harassment and mating attempts.

406 Male mating harassment in Ischnurans is likely to substantial since females mate with

407 multiple males (Cooper et al., 1996) but only require one insemination to produce as many

408 fertile eggs as females that have mated several times (Sirot \& Brockmann, 2001), and more

409 mating attempts are initiated then are carried out (T. Gosden \& E. I. Svensson, unpublished

410 data). This harassment may select for different phenotypic female optima, so that females can

411 avoid such harassment by either becoming a more or less perfect male mimic (i. e.

412 Androchromes) or by developing a divergent phenotype in colour and shape (i. e. Infuscans-

413 obsoleta) or by becoming so different that it falls outside the usual range of female

414 phenotypes encountered by males. Interestingly, Infuscans-obsoleta is also the morph that is

415 found least frequently in copula in the field, relative to their frequency in the population

416 (Svensson et al., 2005).

418 These adaptive explanations for the phenotypic integration in female morphs are consistent

419 with both models and data that that indicate intraspecific genetic diversification is an expected 420 outcome of male mating harassment (Gavrilets \& Waxman, 2002), particularly if males have

421 visual or other perceptive constraints that force them to develop a search image for only one

422 female morph at a time (Fincke, 2004; Svensson et al., 2005). Such intraspecific divergence 
423 has two possible outcomes: it could subsequently promote speciation, or constrain it by

424 eliminating selection pressures for additional divergence through the formation of stable

425 female genetic clusters (polymorphism; Svensson et al., 2005).

427 Finally, although differences between these morphs in shape are relatively modest relative to

428 interspecific differences (Table 4; Fig. 4B), we note that recombination is expected to limit

429 intraspecific divergence between sympatric morphs of this kind (Sinervo \& Svensson, 2002).

430 Hence, although the fitness optima of the morphs may differ substantially, realized (observed)

431 differences in nature between morphs will be more moderate in magnitude, due to the

432 constraining effects of recombination (Table 4; Fig. 4B).

434 Fitness consequences of variation in size and shape: internal selection on morphology?

436 We found evidence for fitness consequences on morphology in the larval stage, since

437 individuals that managed to emerge successfully differed in both size and shape (PC1 and

438 PC2) from those that did not. Surprisingly, individuals that emerged started off smaller in size

439 than those that did not (Figure 1D). There are two possible explanations for this pattern,

440 antagonistic pleiotropy and competition. In antagonistic pleiotropy, alleles with positive

441 effects early in development have negative effects later in development (Rose, 1982).

442 Alternatively, there could be differences in competitive ability which are the result of a trade-

443 off between growth rate while under intraspecific competition and growth rate when solitary,

444 since larvae were not moved to individual enclosures until a few weeks after hatching. Such

445 trade-offs between growth rate under crowded an non-crowded conditions have indeed been

446 documented previously in laboratory selection experiments of Drosophila (Mueller \& Ayala,

447 1981; Mueller, 1988; Borash et al., 1998). 
449 Since individuals that emerged successfully differed in body shape from those that did not,

450 this suggests that there is selection on body shape in the larval stage. This type of selection

451 could contribute to the build-up of linkage disequilibrium in the female morphs (see above).

452 Individuals that emerged had shorter abdomens and longer wings than those that did not, so

453 there appears to be some sort of internal ("non-ecological") selection on shape. Internal

454 selection refers to selection that acts on organismal traits independently of ecology (Schwenk

455 \& Wagner, 2001). Internal selection caused by developmental problems is more likely in this

456 laboratory study in which predators and other ecological agents of selection can be excluded

457 as mortality causes. The fact that this type of internal selection appeared to favour shorter

458 wings (see Results) is particularly interesting and may indicate that there may be development

459 fitness costs of long wings that may counteract selection for longer wings or larger size at the

460 adult stage (Kingsolver \& Pfennig, 2004). The relevance of such selection in the field is

461 unknown, but could be important if mortality due to other causes (such as predation) is

462 random with respect to an individual's ability to emerge successfully.

464 Conclusions

466 We have found evidence of phenotypic integration of many traits in the female morphs, such

467 as colour pattern, morphology, developmental rate (this study), development time (Abbott \&

468 Svensson, 2005), and fecundity (Svensson et al., 2005; Svensson \& Abbott, 2005). These and

469 other results reveals the similarities between the development of morphological differences of

470 heritable morphs in Ischnura elegans and the development of sexual dimorphism in both this

471 insect and vertebrate species (Badyaev, 2002). Both these phenomena can be analysed and

472 understood in terms of the interactive effects of developmental rate and development time, 
473 two factors which can enhance or counteract each other during the course of development. We

474 are currently investigating sexual dimorphism and phenotypic integration in field-caught

475 adults, genetic correlations and heritability of morphological traits, and are also analyzing

476 larval morphology using geometric morphometric techniques. Other interesting questions for

477 further research include the relative importance of maternal effects, pleiotropy, and linkage

478 disequilibrium (of linked or unlinked loci) in producing morph-related differences, and the

479 effect of competition on development of adult phenotypes.

481 Acknowledgements

483 We are grateful to S. Baumgartner for supplying Drosophila, and to A. Coreau, H. Hogfors 484 and M. Gustafsson for assistance in the laboratory and in the field. We also wish to thank R.

485 Härdling, T. Gosden, F. Eroukmanhoff, K. Karlsson, and H. Ivarsson for comments on the 486 first draft of this manuscript. This study is part of a long-term study of the ecological genetics 487 and evolutionary biology of I. elegans. Financial support has been provided by the Swedish 488 Research Council and Oscar \& Lilli Lamms Stiftelse (to E. S.). 
491 Abbott, J. and Svensson, E. I. 2005. Phenotypic and genetic variation in emergence and 492 development time of a trimorphic damselfly. J. Evol. Biol. 18: 1464-1470.

493

494 Arthur, W. 2002. The emerging conceptual framework of evolutionary developmental 495 biology. Nature 415: 757-764.

496

497 Askew, R. R. 1988. The dragonflies of Europe. Harley Books, Colchester, Essex.

498 Badyaev, A. V. 2002. Growing apart: an ontogenetic perspective on the evolution of sexual 499 size dimorphism. Trends Ecol. Evol. 17: 369-378.

501 Badyaev, A. V. 2004a. Developmental perspective on the evolution of sexual ornaments.

502 Evolutionary Ecology Research 6: 975-991.

504 Badyaev, A. V. 2004b. Integration and modularity in the evolution of sexual ornaments: an 505 overlooked perspective. Pigliucci, M. and Preston, K. (eds). Phenotypic integration: studying 506 the ecology and evolution of complex phenotypes. [3], 50-79. Oxford University Press, Inc., 507 Oxford. 
508 Badyaev, A. V., Hill, G. E., Dunn, P. O., and Glen, J. C. 2001a. Plumage color as a composite 509 trait: developmental and functional integration of sexual ornamentation. Am. Nat. 158: 221510235.

512 Badyaev, A. V., Whittingham, L. A., and Hill, G. E. 2001b. The evolution of sexual size

513 dimorphism in the house finch. III. Developmental basis. Evolution 55: 176-189.

515 Banks, M. J. and Thompson, D. J. 1987. Regulation of damselfly populations: the effects of

516 larval density on larval survival, development rate and size in the field. Freshwater Biol. 17:

$517 \quad 357-365$.

519 Benke, A. C. 1970. A method for comparing individual growth rates of aquatic insects with 520 special reference to the Odonata. Ecology 51: 328-331.

Bolnick, D. I. and Doebeli, M. 2003. Sexual dimorphism and adaptive speciation: two sides of the same ecological coin. Evolution 57: 2433-2449. 
528 Brodie, E. D., III. 1992. Correlational selection for colour pattern and antipredator behavior in

529 the garter snake Thamnophis ordinoides. Evolution 46: 1284-1298.

530

531 Carchini, G., Chiarotti, F., Di Domenico, M., and Paganotti, G. 2000. Fluctuating asymmetry,

532 size and mating success in males of Ischnura elegans (Vander Linden) (Odonata:

533 Coenagrionidae). Anim. Behav. 59: 177-182.

534

535 Cooper, G., Miller, P. L., and Holland, P. W. H. 1996. Molecular genetic analysis of sperm

536 competition in the damselfly Ischnura elegans (Vander Linden). Proc. R. Soc. Lond. B Biol.

537 Sci. 263: 1343-1349.

538

539 Corbet, P. S. 1999. Dragonflies: behaviour and ecology of Odonata. Harley Books,

540 Colchester, Essex.

541 Cordero, A. 1990. The inheritance of female polymorphism in the damselfly Ischnura

542 graellsii (Rambur) (Odonata: Coenagrionidae). Heredity 64: 341-346.

543

544 Cordero, A. 1991. Fecundity of Ischnura graellsii (Rambur) in the laboratory (Zygoptera:

545 Coenagrionidae). Odonatologica 20: 37-44.

546 
547 Cordero, A. 1992a. Density-dependent mating success and colour polymorphism in females of

548 the damselfly Ischnura graellsii (Odonata: Coenagrionidae). J. Anim. Ecol. 61: 769-780.

549

550 Cordero, A. 1992b. Morphological variability, female polymorphism and heritability of body

551 length in Ischnura graellsii (Rambur) (Zygoptera: Coenagrionidae). Odonatologica 21: 409-

552419.

553

554 Cordero, A., Santolamazza Carbone, S., and Utzeri, C. 1997. Male mating success in a natural

555 population of Ischnura elegans (Vander Linden) (Odonata: Coenagrionidae). Odonatologica

556 26: 459-465.

557

558

Cordero, A., Santolamazza Carbone, S., and Utzeri, C. 1998. Mating opportunities and mating

559

costs are reduced in androchrome female damselflies, Ischnura elegans (Odonata). Anim.

560

Behav. 55: 185-197.

561

562 de Block, M. and Stoks, R. 2003. Adaptive sex-specific life history plasticity to temperature

563 and photoperiod in a damselfly. J. Evol. Biol. 16: 986-995.

564

565 Fincke, O. M. 2004. Polymorphic signals of harassed female odonates and the males that learn

566 them support a novel frequency-dependent model. Anim. Behav. 67: 833-845. 
568 Fry, J. D. 1992. The mixed-model analysis of variance applied to quantitative genetics:

569 biological meaning of the parameters. Evolution 46: 540-550.

570

571 Gavrilets, S. and Waxman, D. 2002. Sympatric speciation by sexual conflict. Proc. Nat. Acad.

572 Sci. USA 99: 10533-10538.

573

574 Gilbert, S. F. 2001. Ecological developmental biology: developmental biology meets the real

575 world. Developmental Biology 233: 1-12.

576

577 Harvey, I. F. and Corbet, P. S. 1985. Territorial behaviour of larvae enhances mating success

578 of male dragonflies. Anim. Behav. 33: 561-565.

579

580 Jackson, J. E. 1991. A user's guide to principal components. John Wiley \& Sons, Inc., New

581 York.

582 Kingsolver, J. G. and Pfennig, D. W. 2004. Individual-level selection as a cause of Cope's

583 Rule of phyletic size increase. Evolution 58: 1608-1612.

584

585 Leimar, O. 2005. The evolution of phenotypic polymorphism: randomized strategies versus

586 evolutionary branching. Am. Nat. 165: 669-681.

587 
588

589 mixed models. SAS Institute Inc., Cary, NC.

590

Lynch, M. and Walsh, B. 1998. Genetics and analysis of quantitative traits. Sinauer

591

Associates, Inc., Sunderland, MA.

592

McGlothlin, J. W., Parker, P. G., Nolan, V., Jr., and Ketterson, E. D. 2005. Correlational

593

selection leads to genetic integration of body size and an attractive plumage trait in Dark-eyed

594 Juncos. Evolution 59: 658-671.

595

596

Morbey, Y. E. and Ydenberg, R. C. 2001. Protandrous arrival timing to breeding ares: a

597 review. Ecology Letters 4: 663-673.

598

599 Mueller, L. D. 1988. Evolution of competitive ability in Drosophila by density-dependent

600 natural selection. Proc. Nat. Acad. Sci. USA 85: 4383-4386.

601

602 Mueller, L. D. and Ayala, F. J. 1981. Trade-off between $r$-selection and $K$-selection in

603 Drosophila populations. Proc. Nat. Acad. Sci. USA 78: 1303-1305.

604

605

606

phenotypes. Ecology Letters 6: 265-272.

607 
608 Pigliucci, M. and Preston, K. 2004. Phenotypic integration: studying the ecology and

609 evolution of complex phenotypes. Pigliucci, M. and Preston, K. Oxford University Press,

610 Oxford.

611 Rice, W. R. and Chippindale, A. K. 2001. Intersexual ontogenetic conflict. J. Evol. Biol. 14:

$612685-693$.

613

614 Rose, M. R. 1982. Antagonistic pleiotropy, dominance and genetic variation. Heredity 48: 6361578.

616

617 Sánchez-Guillén, R. A., Van Gossum, H., and Cordero Rivera, A. 2005. Hybridization and the

618 inheritance of female colour polymorphism in two Ischnurid damselflies (Odonata:

619 Coenagrionidae). Biol. J. Linn. Soc. 85: 471-481.

620

621 Schluter, D. 1996. Adaptive radiation along genetic lines of least resistance. Evolution 50:

$622 \quad 1766-1774$.

623

624 Schwenk, K. and Wagner, G. P. 2001. Function and the evolution of phenotypic stability:

625 connecting pattern to process. Am. Zool. 41: 552-563.

626 
627 Shuster, S. M. and Sassaman, C. 1997. Genetic interaction between male mating strategy and

628 sex ration in a marine isopod. Nature 388: $373-377$.

629

630 Sinervo, B. and Lively, C. M. 1996. The rock-paper-scissors game and the evolution of

631 alternative male strategies. Nature 380: 240-243.

632

633 Sinervo, B. and Svensson, E. 2002. Correlational selection and the evolution of genomic

634 architecture. Heredity 89: 329-338.

635

636 Sinervo, B., Svensson, E., and Comendant, T. 2000. Density cycles and an offspring quantity

637 and quality game driven by natural selection. Nature 406: 985-988.

638

639 Sinervo, B. and Svensson, E. I. 2004. The origin of novel phenotypes: correlational selection,

640 epistasis, and speciation. Hall, B. K., Pearson, R. D., and Müller, G. B. (eds). Environment,

641 development, and evolution: toward a synthesis. [11], 171-194. The MIT Press, Cambridge,

642 MA.

643 Sirot, L. K. and Brockmann, H. J. 2001. Costs of sexual interactions to females in Rambur's

644 forktail damselfly, Ischnura ramburi (Zygoptera: Coenagrionidae). Anim. Behav. 61: 415-424.

645 
646 Stoks, R., McPeek, M. A., and Mitchell, J. L. 2003. Evolution of prey behavior in response to

647 changes in predation regime: damselflies in fish and dragonfly lakes. Evolution 57: 574-585.

648

649 Stoks, R., Nystrom, J. L., May, M. L., and McPeek, M. A. 2005. Parallel evolution in

650 ecological and reproductive traits to produce cryptic damselfly species across the holarctic.

651 Evolution 59: 1976-1988.

652

653 Svensson, E., Sinervo, B., and Comendant, T. 2001. Condition, genotype-by-environment

654 interaction, and correlational selection in lizard life-history morphs. Evolution 55: 2053-2069.

655

656 Svensson, E. I. and Abbott, J. 2005. Evolutionary dynamics and population biology of a

657 polymorphic insect. J. Evol. Biol. 18: 1503-1514.

658

659 Svensson, E. I., Abbott, J., and Härdling, R. 2005. Female polymorphism, frequency-

660 dependence and rapid evolutionary dynamics in natural populations. Am. Nat. 165: 567-576.

661

662 Van Gossum, H., Stoks, R., and De Bruyn, L. 2001. Frequency-dependent male mate

663 harassment and intra-specific variation in its avoidance by females of the damselfly Ischnura

664 elegans. Behav. Ecol. Sociobiol. 51: 69-75.

665 
666 West-Eberhard, M. J. 2003. Developmental plasticity and evolution. Oxford University Press,

667 Oxford.

668

669 
Table 1: Factor loadings for PC1 and PC2 in the larval stage. PC1 is a measure of overall size, while PC2 mostly represents a trade-off in wing length and abdomen length.

Measurement Loading PC1 Loading PC2

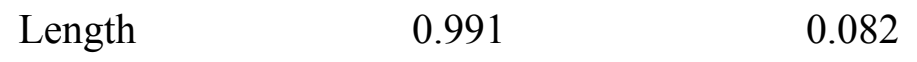

$\begin{array}{lll}\text { Abdomen } & 0.987 & 0.121\end{array}$

$\begin{array}{lll}\text { Thorax } & 0.993 & 0.013\end{array}$

$\begin{array}{lll}\text { S4 } & 0.983 & 0.093\end{array}$

Wing $\quad 0.946 \quad-0.323$ 
Table 2: Table of repeated measures analysis of effects of Sex, Maternal morph, Own morph, and Emergence on PC1 (body size) in the larval stage. Family was included as a random factor in all analyses, except Own morph, where it is a fixed factor (see text). A significant effect of the factor indicates significant differences in the intercepts of the trajectories, a significant interaction between the factor and time indicates significant differences in the slope of the trajectories, and a significant interaction between the factor and time ${ }^{2}$ indicates significant differences in the curvature of the trajectories. For fixed effects (Maternal morph, Sex, Own morph, Emergence) the test statistic is F, for random effects (Family) it is Z.

Effect Num Df Den Df F

Z

P-value

$\operatorname{Sex}(\mathrm{N}=632)$ :

Sex

2

185

6.46

0.0019

Sex*time

2

565

5567.42

$<0.0001$

Sex time $^{2}$

2

575

169.73

$<0.0001$

Family

78

3.60

0.0002

Maternal morph $(\mathrm{N}=622)$ :

Maternal morph

3

105

2.81

0.0429

Maternal morph*time

3

562

3749.10

$<0.0001$

Maternal morph*time ${ }^{2}$

3

574

124.71

$<0.0001$

Family

77

3.54

0.0002

Own morph (females only, $\mathrm{N}=229$ ): 


\begin{tabular}{|c|c|c|c|c|}
\hline Own morph & 3 & 139 & 0.99 & 0.3973 \\
\hline Own morph*time & 3 & 203 & 1395.54 & $<0.0001$ \\
\hline Own morph*time ${ }^{2}$ & 3 & 199 & 47.45 & $<0.0001$ \\
\hline Family & 76 & 53.3 & 1.91 & 0.0066 \\
\hline \multicolumn{5}{|l|}{ Emergence $(\mathrm{N}=628)$ : } \\
\hline Emergence & 2 & 232 & 3.17 & 0.0440 \\
\hline Emergence*time & 2 & 543 & 5586.27 & $<0.0001$ \\
\hline Emergence $^{*}$ time $^{2}$ & 2 & 553 & 172.05 & $<0.0001$ \\
\hline Family & 78 & & & 0.0002 \\
\hline
\end{tabular}


Table 3: Table of repeated measures analysis of effects of Sex, Maternal morph, Own morph, and Emergence on PC2 (body shape) in the larval stage. Family was included as a random factor in all analyses. A significant effect of the factor indicates significant differences in the intercepts of the trajectories, a significant interaction between the factor and time indicates significant differences in the slope of the trajectories, and a significant interaction between the factor and time ${ }^{2}$ indicates significant differences in the curvature of the trajectories. For fixed effects (Maternal morph, Sex, Own morph, Emergence) the test statistic is F, for random effects (Family) it is Z.

Effect Num Df Den Df F

Z

P-value

$\operatorname{Sex}(\mathrm{N}=632)$ :

Sex

2

151

2.45

0.0895

Sex*time

2

546

13.82

$<0.0001$

Sex $*$ time $^{2}$

2

561

1148.64

$<0.0001$

Family

78

4.40

$<0.0001$

Maternal morph $(\mathrm{N}=622)$ :

Maternal morph 3

86

0.48

0.6943

Maternal morph*time

3

537

9.10

$<0.0001$

Maternal morph*time ${ }^{2}$

3

551

728.88

$<0.0001$

Family

77

4.34

$<0.0001$

Own morph (females only, $\mathrm{N}=229$ ): 


\begin{tabular}{|c|c|c|c|c|c|}
\hline Own morph & 3 & 185 & 2.33 & & 0.0761 \\
\hline Own morph*time & 3 & 215 & 4.81 & & 0.0029 \\
\hline Own morph*time ${ }^{2}$ & 3 & 218 & 417.54 & & $<0.0001$ \\
\hline Family & 76 & & & 3.37 & 0.0004 \\
\hline \multicolumn{6}{|l|}{ Emergence $(\mathrm{N}=628)$ : } \\
\hline Emergence & 2 & 229 & 0.22 & & 0.7988 \\
\hline Emergence*time & 2 & 531 & 20.04 & & $<0.0001$ \\
\hline Emergence $^{*}$ time $^{2}$ & 2 & 541 & 1217.44 & & $<0.0001$ \\
\hline Family & 78 & & & 4.39 & $<0.0001$ \\
\hline
\end{tabular}


Table 4: LS means of A) morphological measurements and PCs in the final instar according to Sex, Maternal morph, Own morph, and Emergence and B) morphological measurements in the adult stage according to Sex and Own morph. All values were calculated from mixed models with family as a random factor and are presented in the form Mean (SE).

Morphological measurements (total length, abdomen length, thorax width, width of the $4^{\text {th }}$ segment of the abdomen, and wing pad length) are in $\mathrm{mm}$.

A)

Sex:

\begin{tabular}{lll} 
& \multicolumn{1}{l}{ Female } & Male \\
Length & $15.13(0.07)$ & $14.70(0.07)$ \\
Abdomen & $10.12(0.04)$ & $10.92(0.04)$ \\
Thorax & $2.37(0.007)$ & $2.28(0.006)$ \\
S4 & $1.45(0.005)$ & $1.36(0.005)$ \\
Wing & $4.47(0.017)$ & $4.20(0.016)$ \\
PC1 & $1.50(0.016)$ & $1.31(0.016)$ \\
PC2 & $-0.87(0.032)$ & $-0.84(0.030)$
\end{tabular}

Maternal morph:

$\begin{array}{llll} & \text { Androchrome } & \text { Infuscans } & \text { Infuscans-obsoleta } \\ \text { Length } & 14.90(0.10) & 14.83(0.12) & 14.96(0.13) \\ \text { Abdomen } & 10.00(0.05) & 9.99(0.07) & 10.06(0.07) \\ \text { Thorax } & 2.33(0.009) & 2.31(0.011) & 2.32(0.012) \\ \text { S4 } & 1.41(0.006) & 1.40(0.008) & 1.40(0.009)\end{array}$




$\begin{array}{llll}\text { Wing } & 4.34(0.022) & 4.29(0.029) & 4.35(0.029) \\ \text { PC1 } & 1.40(0.022) & 1.37(0.029) & 1.42(0.030) \\ \text { PC2 } & -0.87(0.032) & -0.83((0.052) & -0.85(0.053)\end{array}$

Own morph:

$\begin{array}{llll} & \text { Androchrome } & \text { Infuscans } & \text { Infuscans-obsoleta } \\ \text { Length } & 15.40(0.09) & 14.95(0.11) & 14.98(0.23) \\ \text { Abdomen } & 10.27(0.05) & 10.04(0.06) & 10.02(0.12) \\ \text { Thorax } & 2.39(0.009) & 2.35(0.010) & 2.37(0.022) \\ \text { S4 } & 1.46(0.006) & 1.44(0.006) & 1.46(0.014) \\ \text { Wing } & 4.54(0.022) & 4.45(0.024) & 4.44(0.052) \\ \text { PC1 } & 1.57(0.022) & 1.47(0.025) & 1.49(0.053) \\ \text { PC2 } & -0.82(0.036) & -0.93(0.040) & -0.85(0.086)\end{array}$

Emergence:

Unsuccessful Successful

$\begin{array}{lll}\text { Length } & 14.37(0.14) & 14.94(0.06) \\ \text { Abdomen } & 9.70(0.08) & 10.04(0.04) \\ \text { Thorax } & 2.27(0.014) & 2.32(0.006) \\ \text { S4 } & 1.39(0.011) & 1.40(0.004) \\ \text { Wing } & 4.29(0.039) & 4.33(0.015) \\ \text { PC1 } & 1.29(0.034) & 1.41(0.015) \\ \text { PC2 } & -1.10(0.061) & -0.84(0.027)\end{array}$

B) 
Sex:

\begin{tabular}{lll} 
& \multicolumn{1}{l}{ Female } & Male \\
Length & $30.07(0.10)$ & $30.06(0.09)$ \\
Abdomen & $23.54(0.08)$ & $23.78(0.08)$ \\
Thorax & $2.19(0.007)$ & $2.09(0.006)$ \\
S4 & $0.73(0.004)$ & $0.62(0.003)$ \\
Wing & $18.77(0.06)$ & $17.10(0.05)$
\end{tabular}

Own morph:

$\begin{array}{llll} & \text { Androchrome } & \text { Infuscans } & \text { Infuscans-obsoleta } \\ \text { Length } & 30.20(0.13) & 30.06(0.15) & 29.61(0.30) \\ \text { Abdomen } & 23.62(0.11) & 23.58(0.12) & 23.10(0.25) \\ \text { Thorax } & 2.20(0.010) & 2.18(0.011) & 2.21(0.022) \\ \text { S4 } & 0.72(0.005) & 0.73(0.005) & 0.75(0.011) \\ \text { Wing } & 18.85(0.08) & 18.75(0.09) & 18.59(0.19)\end{array}$


Table 5: Factor loadings for PC1 and PC2 in laboratory-raised adults. PC1 is a measure of overall size, while PC2 mostly represents a trade-off in wing length/S4 width and total length/ abdomen length.

Measurement Loading PC1 Loading PC2

Length $\quad 0.815 \quad 0.537$

$\begin{array}{lll}\text { Abdomen } & 0.732 & 0.636\end{array}$

$\begin{array}{lll}\text { Thorax } & 0.874 & -0.197\end{array}$

S4 $\quad 0.630 \quad-0.675$

$\begin{array}{lll}\text { Wing } & 0.823 & -0.372\end{array}$ 
Table 6: Table of mixed model analysis of effects of Sex, Maternal morph and Own morph on PC1 (body size) in the adult stage. Family was included as a random factor in all analyses.

Maternal morph and Sex were included in the first analysis (all offspring), and Maternal morph and Own morph in the second (females only). For fixed effects (Maternal morph, Sex, Own morph) the test statistic is F, for random effects (Family) it is Z.

$\begin{array}{llllll}\text { Effect } & \text { Num Df } & \text { Den Df } & \text { F } & Z & P \text {-value }\end{array}$

All individuals $(\mathrm{N}=558)$ :

Maternal morph

Sex

Maternal morph*Sex

Family

77

\section{4}

513

513

0.03

4.08 $<0.0001$

Females only $(\mathrm{N}=232)$ :

Maternal morph

Own morph

Maternal morph*Own morph

Family

\section{2}

2

4 75
108

0.10

217

0.59

216

1.38

0.2405

3.18

0.0007 
Table 7: Table of mixed model analysis of effects of Sex, Maternal morph and Own morph on PC2 (body shape) in the adult stage. Family was included as a random factor in all analyses. Maternal morph and Sex were included in the first analysis (all offspring), and Maternal morph and Own morph in the second (females only). For fixed effects (Maternal morph, Sex, Own morph) the test statistic is F, for random effects (Family) it is Z.

$\begin{array}{llllll}\text { Effect } & \text { Num Df } & \text { Den Df } & \text { F } & Z & P \text {-value }\end{array}$

All individuals $(\mathrm{N}=558)$ :

Maternal morph

Sex

Maternal morph*Sex

Family

Females only $(\mathrm{N}=232)$ :

Maternal morph

Own morph

Maternal morph*Own morph

Family
2

1

2

77

71.2

1.45

0.2409

526

510.29

$<0.0001$

526

1.77

0.1705

3.12

0.0009

0.4205

0.0478

2

207

3.09

0.16

0.9600

204

0.88

0.1905 
Table 8: Table of phenotypic correlations between larval and adult traits. Only correlations between the same trait measured in both stages in the same individual are included (i.e. larval body length in the last instar correlated with adult body length, larval abdomen length in the last instar with adult abdomen length, etc.)

$\begin{array}{lll}\text { Trait } & \mathrm{r} & P \text {-value } \\ \text { Length } & 0.5021 & <0.001 \\ \text { Abdomen } & 0.4358 & <0.001 \\ \text { Thorax } & 0.6527 & <0.001 \\ \text { S4 } & 0.5864 & <0.001 \\ \text { Wing } & 0.7696 & <0.001\end{array}$


Figure legends

Figure 1: The predicted effects of different factors on body size (PC1) in the larval stage. A. The effect of Sex on body size. Females have a higher growth rate than males. B. The effect of Maternal morph on body size. Offspring of Infuscans-obsoleta females have a higher growth rate than offspring of the other morphs. C. The effect of Own morph on body size. Androchrome females have a higher growth rate than females of the other morphs. D. The effect of Emergence on body size. Individuals that emerge have a higher growth rate than individuals that do not emerge, but are smaller initially.

Figure 2: The predicted effects of different factors on body shape (PC2) in the larval stage. A. The effect of Sex on body shape. Males start off with longer wings and shorter abdomens (smaller values of PC2) but end up with shorter wings and longer abdomens than females (larger values). B. The effect of Maternal morph on body shape. Offspring of Infuscans-obsoleta females have shorter wings and longer abdomens (higher values of PC2) than the offspring of the other two morphs. C. The effect of Own morph on body shape. Rank order of the morphs changes several times throughout ontogeny. D. The effect of Emergence on body shape. Individuals that emerge have longer wings and shorter abdomens (lower values of PC2) than individuals that do not emerge.

Figure 3: Difference between males and females in body size (PC1) in the adult stage. Females are significantly larger. 
Figure 4: Differences in body shape (PC2) in the adult stage between A. Males and females. Males have relatively longer abdomens, shorter wings, and narrower S4 than females. B. Females of different morphs. Infuscans-obsoleta females were significantly different $(P<0.05)$ from Androchrome and Infuscans females, with relatively shorter abdomens, longer wings and wider S4. 


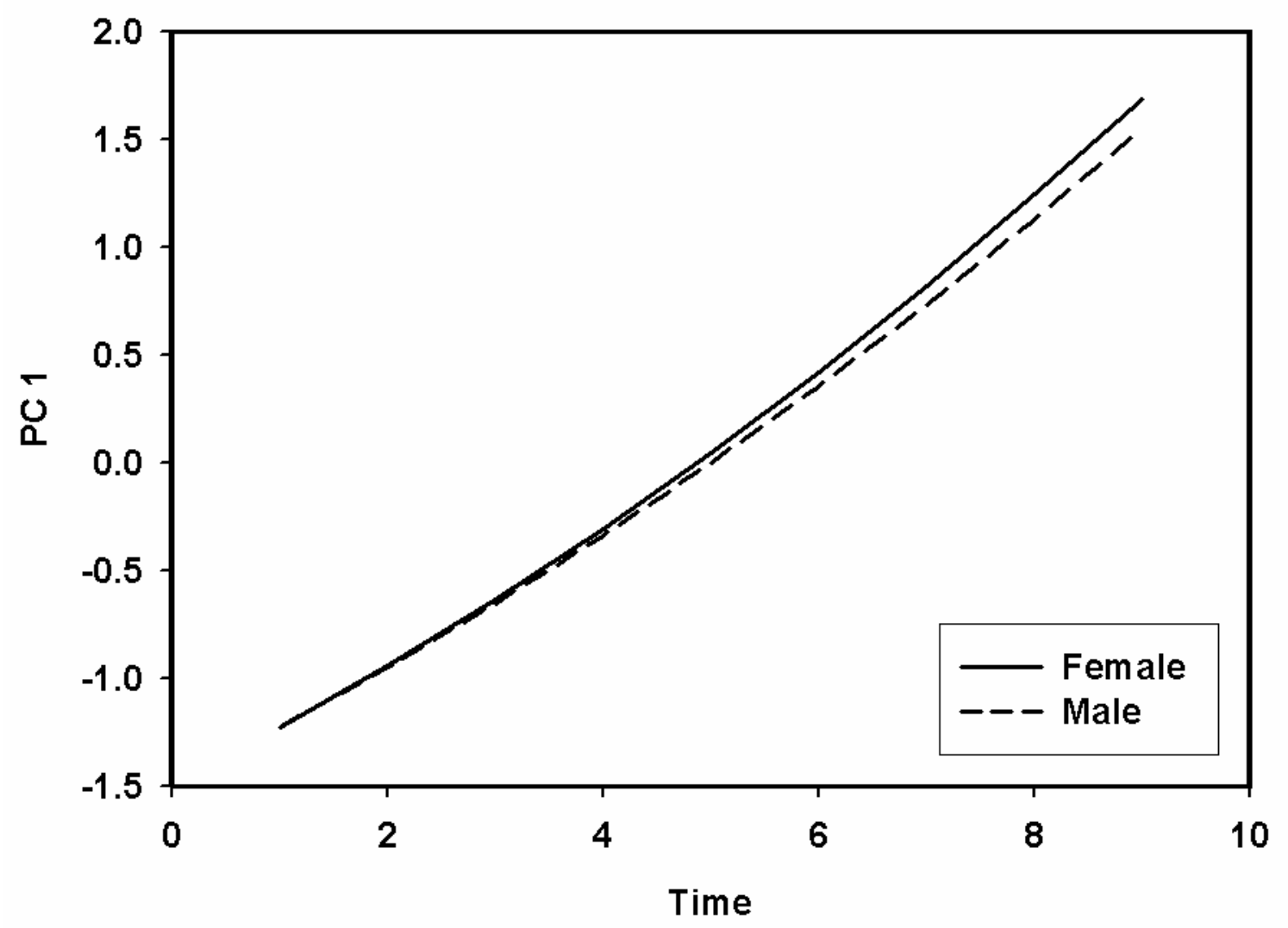

Figure 1A 


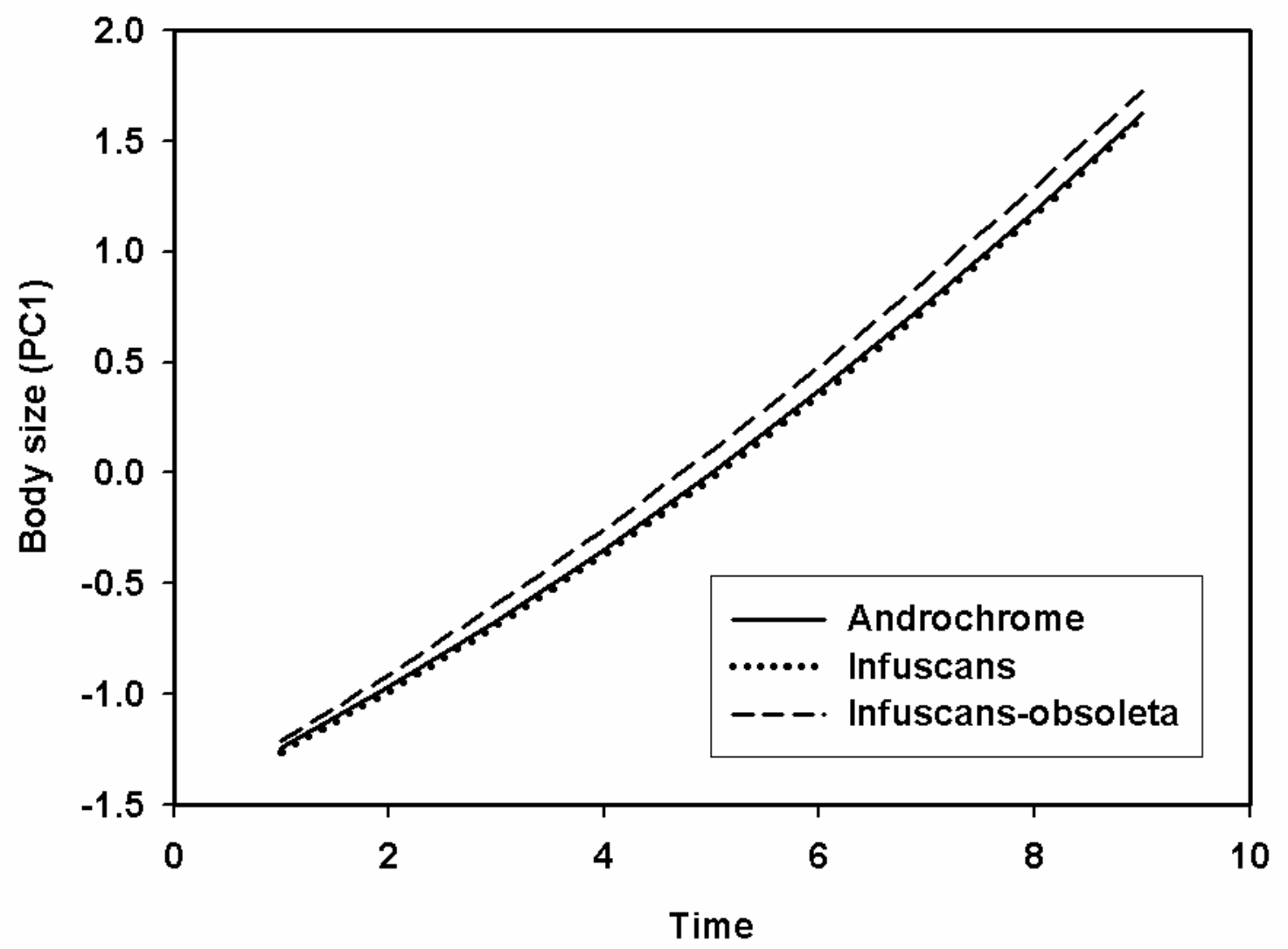

Figure 1B 


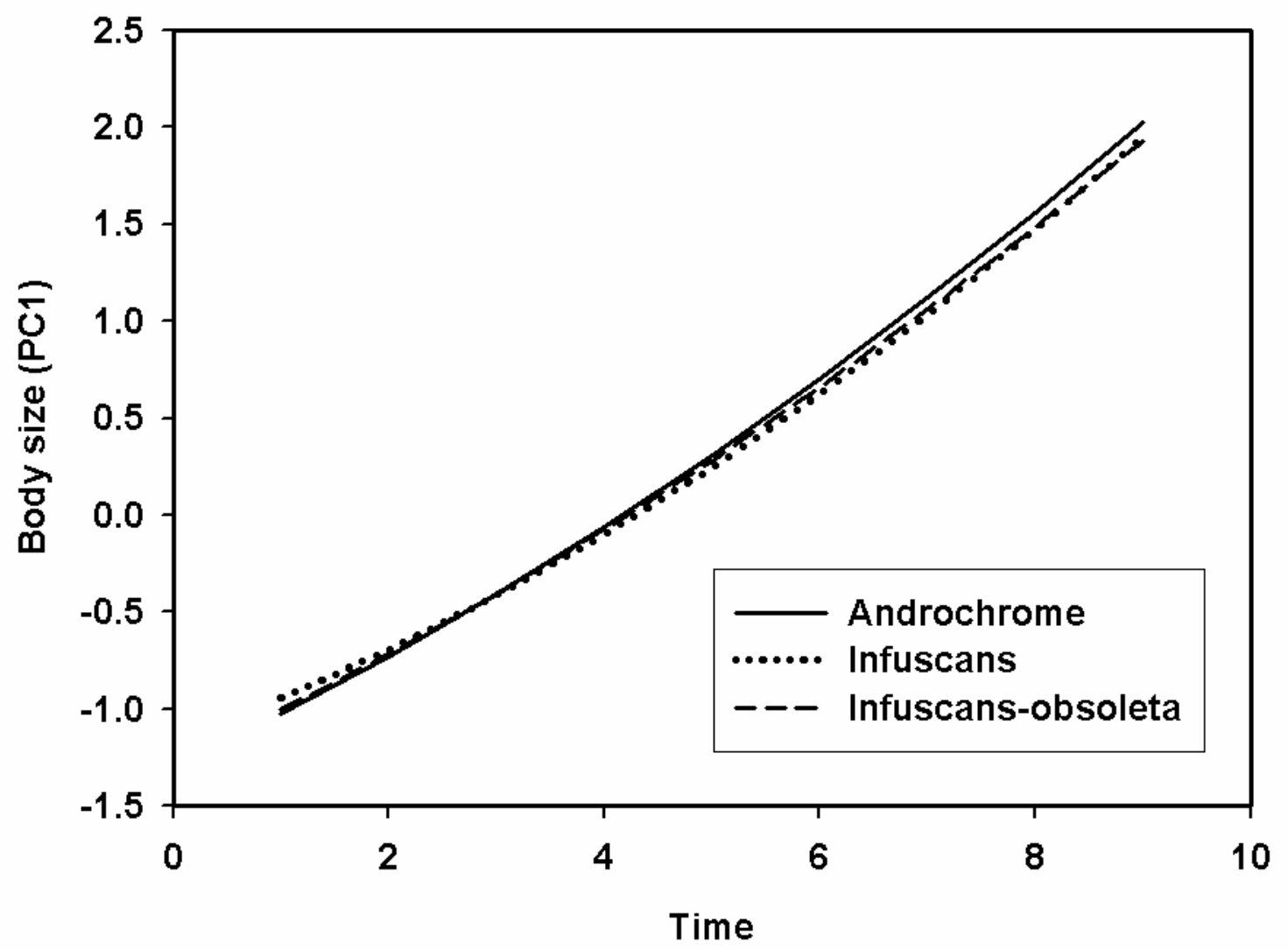

Figure 1C 


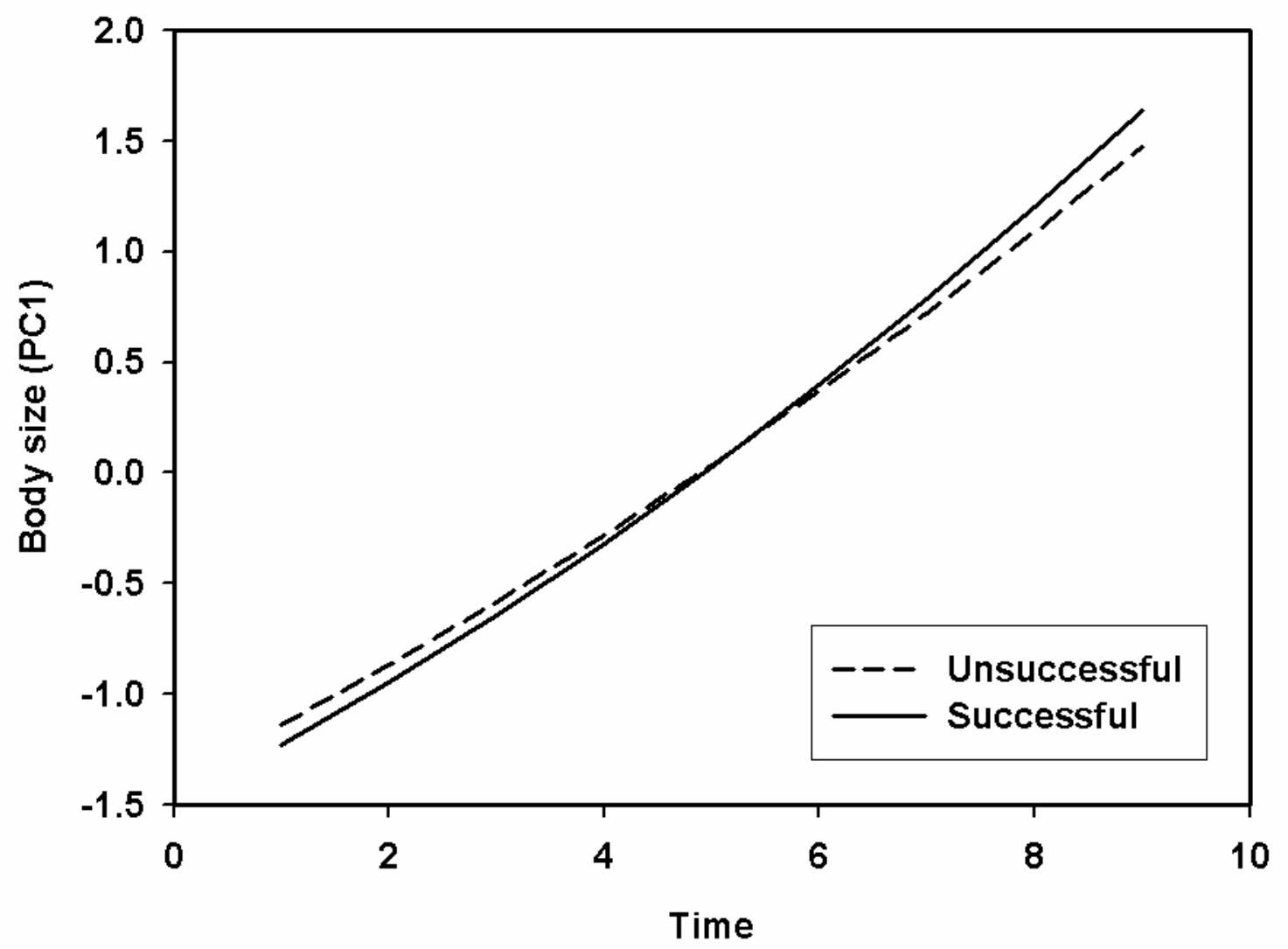

Figure 1D 


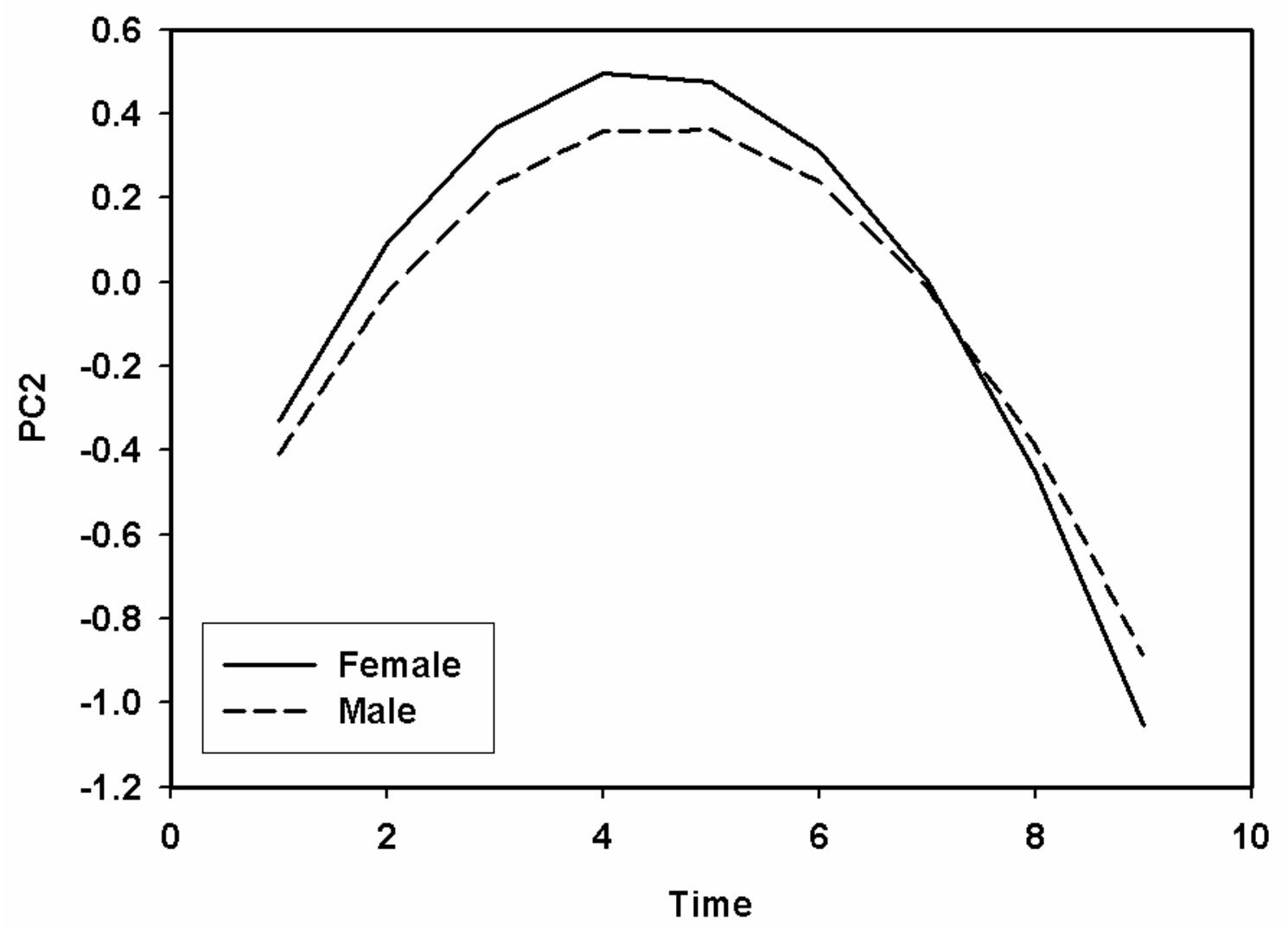

Figure 2A 


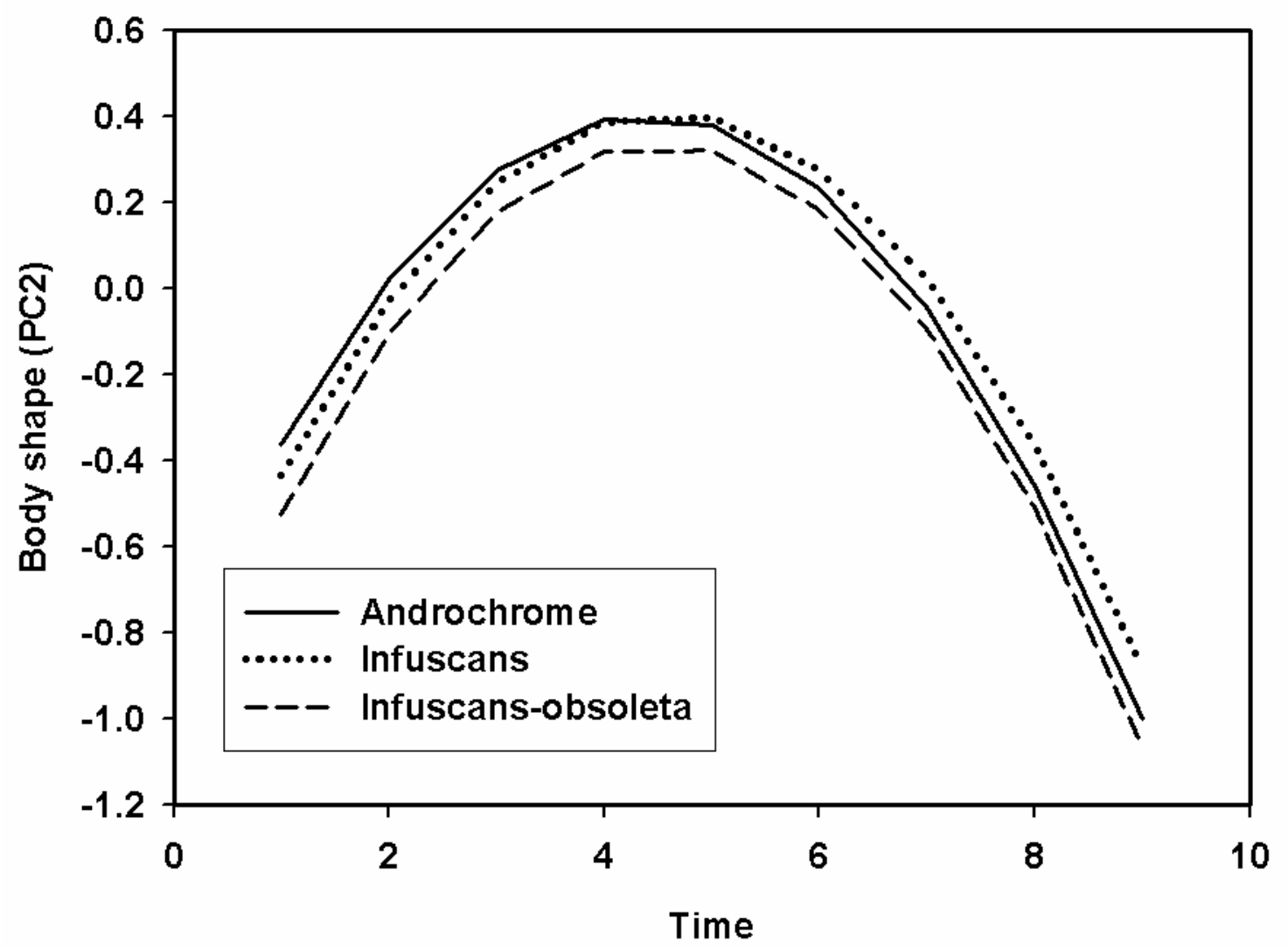

Figure 2B 


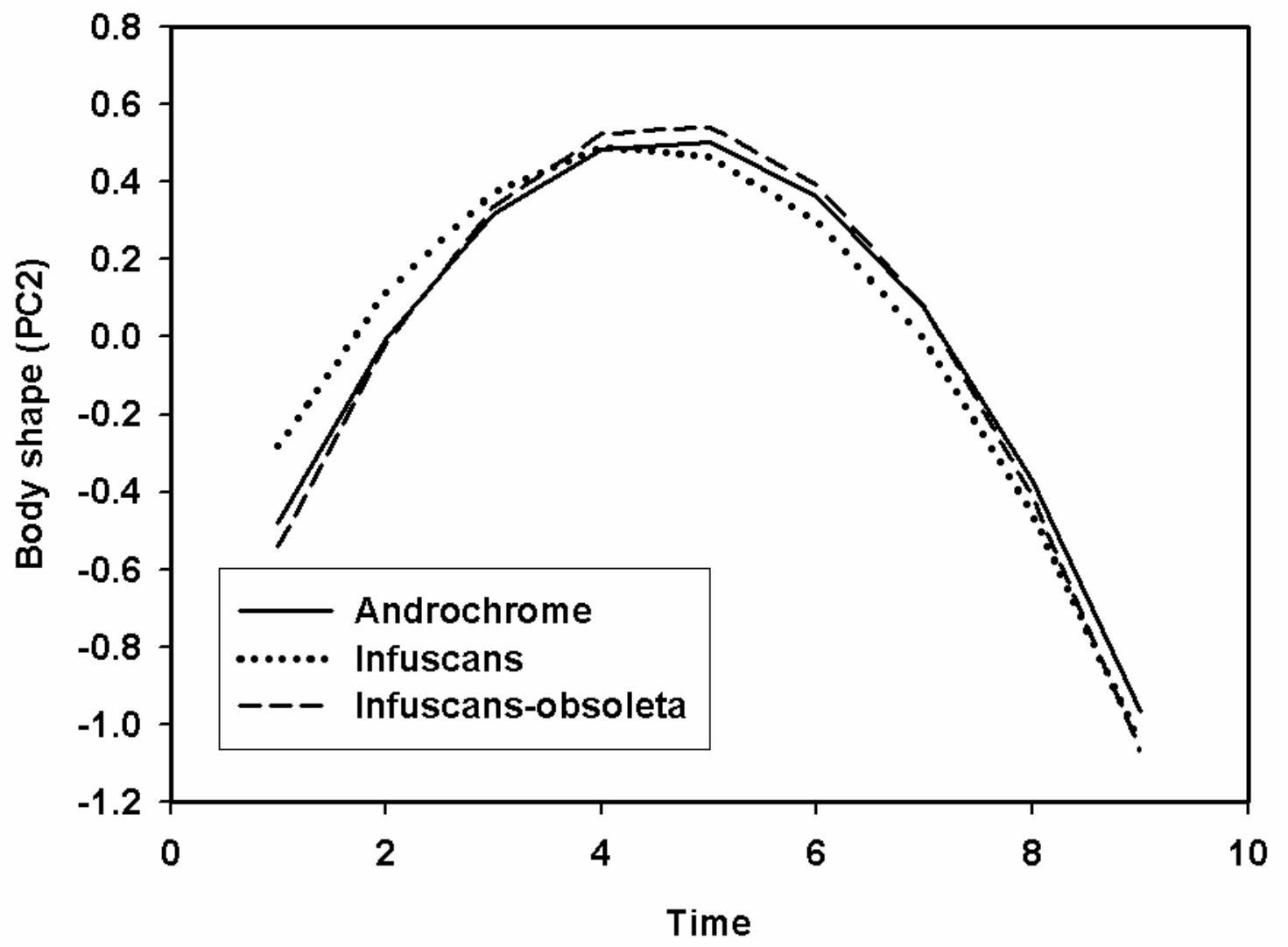

Figure 2C 


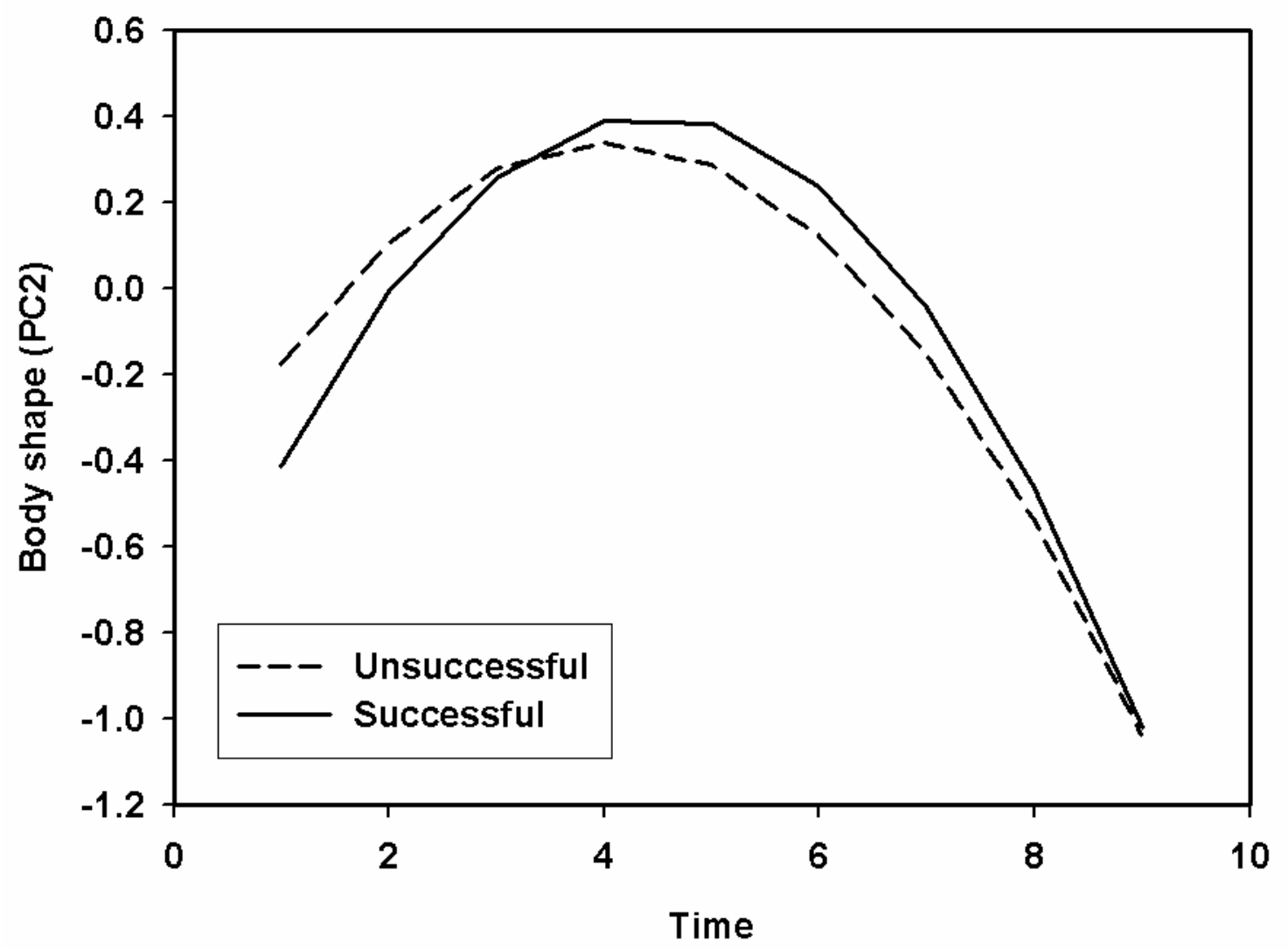

Figure 2D 


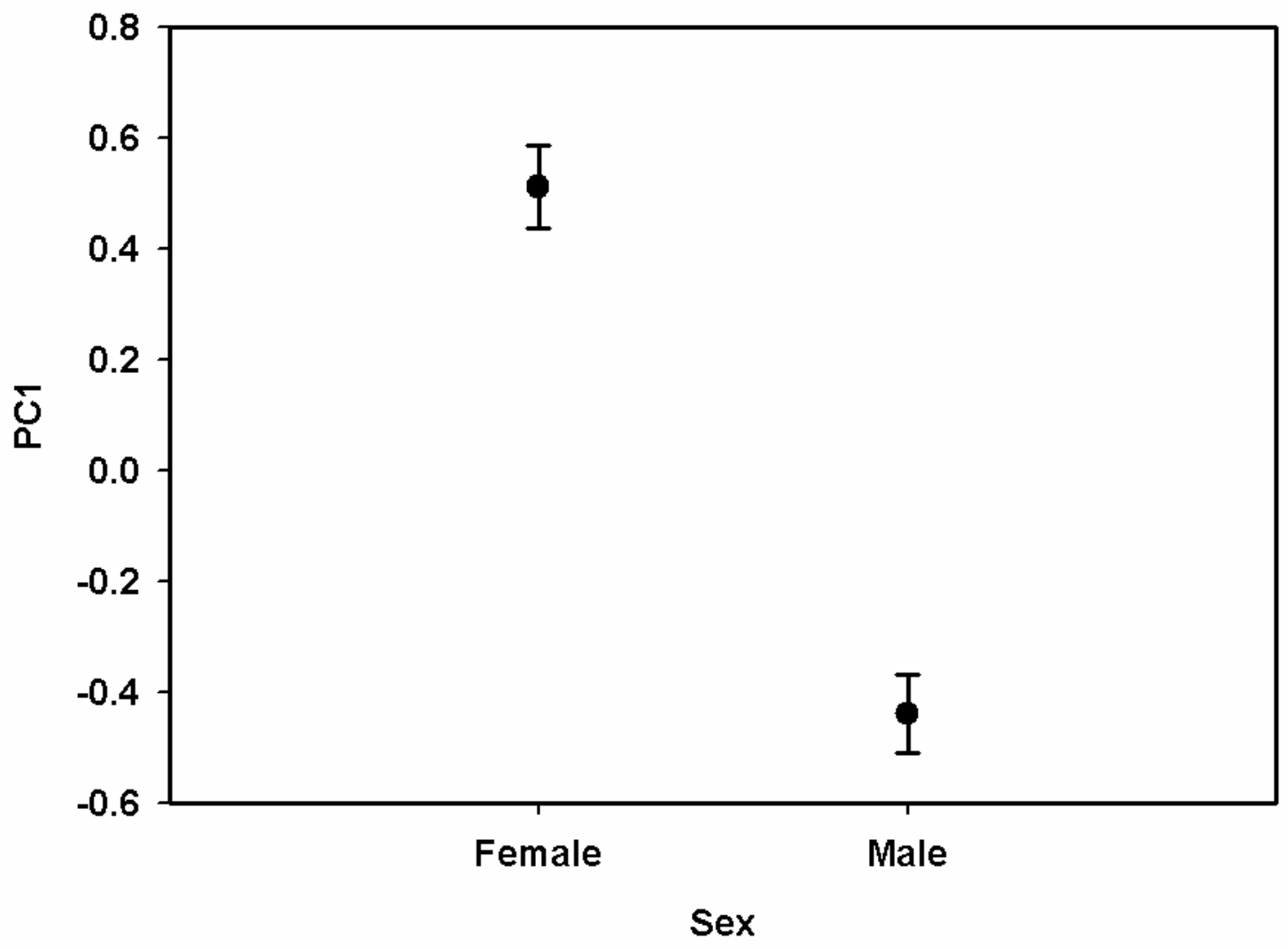

Figure 3 


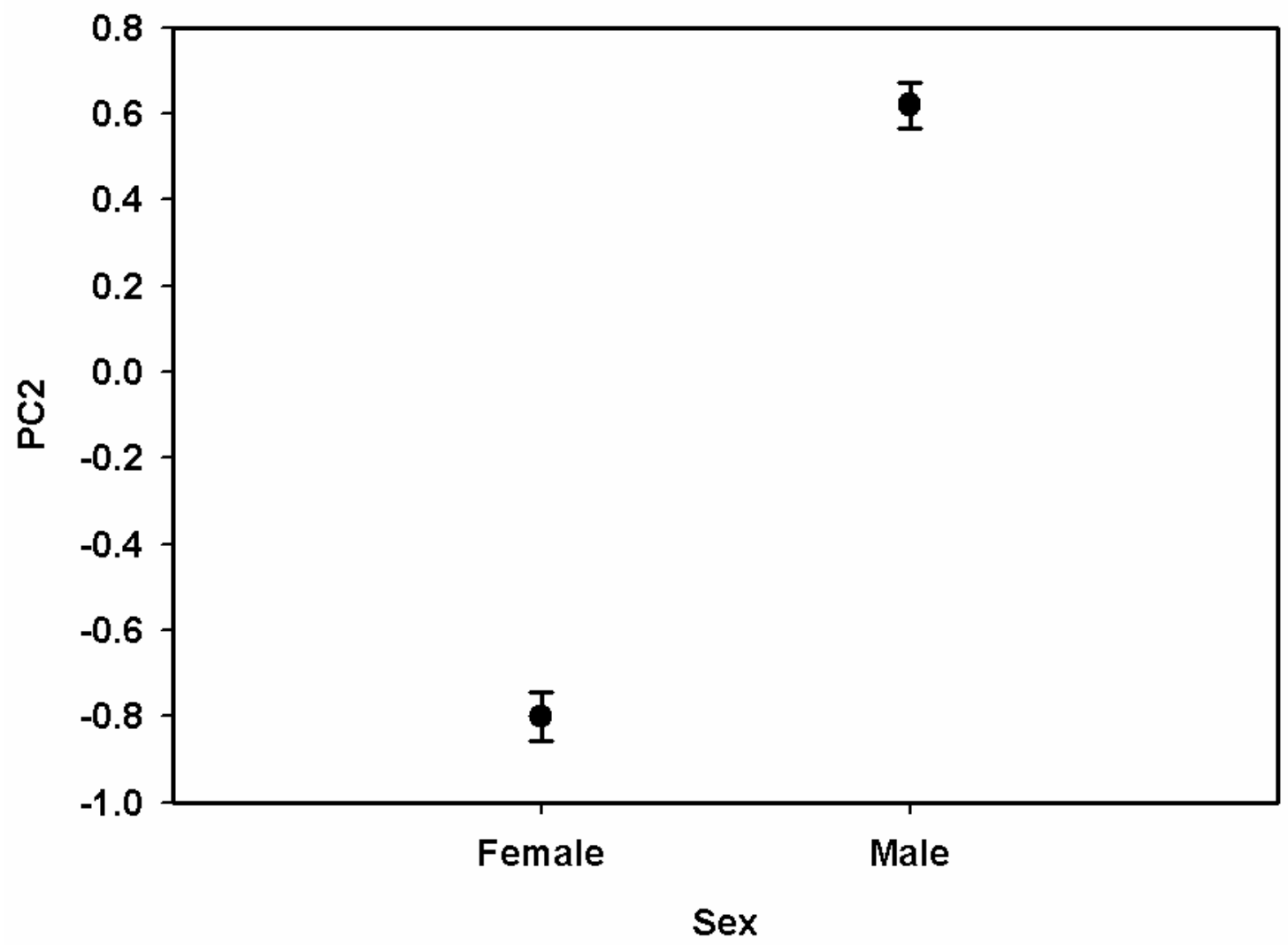

Figure 4A 


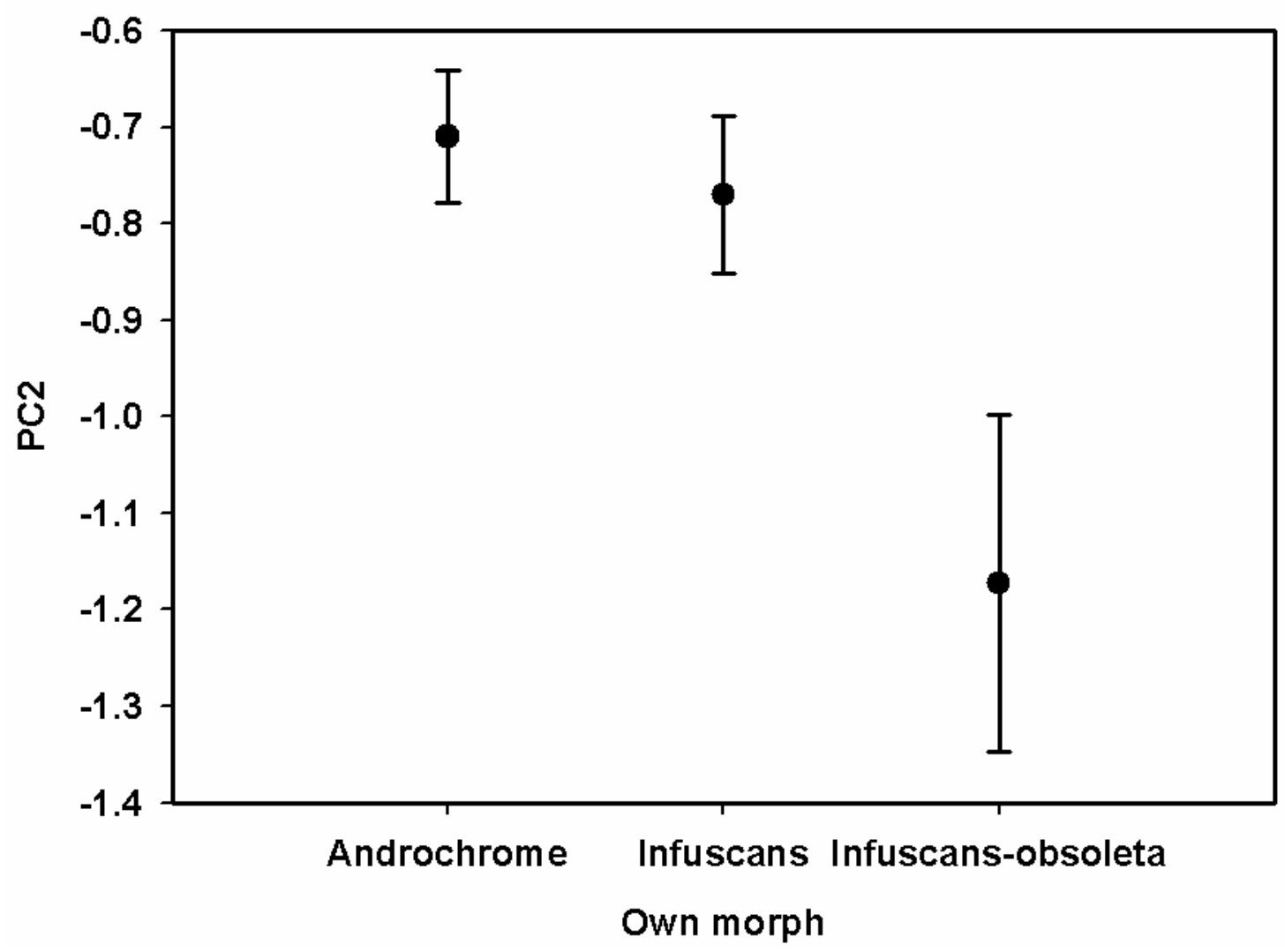

Figure 4B 